\title{
Self-reported Attributes of Police-chiefs Compared to Civil Leadership: Tolerance; Social Interest and Communication
}

\author{
Andersson Arnten $\mathrm{AC}^{* 1}$, Jansson $\mathrm{B}^{2}$, Olsen $\mathrm{K}^{3}$, and Archer $\mathrm{T}^{2}$ \\ ${ }^{1}$ Swedish Police, Department of National Operations, Assessment Functions, Stockholm, Sweden \\ ${ }^{2}$ University of Gothenburg, Department of Psychology, Gothenburg, Sweden \\ ${ }^{3}$ JobMatch Talent, Gothenburg, Sweden
}

${ }^{*}$ Corresponding author: Andersson Arnten AC, Swedish Police, Department of National Operations, Assessment Functions, 10226 Stockholm, Sweden, Tel: +46 722027660, E-mail: acarnten@gmail.com

Citation: Andersson Arnten AC, Jansson B, Olsen K, Archer T (2017) Self-reported Attributes of Policechiefs Compared to Civil Leadership: Tolerance; Social Interest and Communication. J Forensic Sci Criminol 5(5): 503

Received Date: July 31, 2017 Accepted Date: October 30, 2017 Published Date: October 31, 2017

\begin{abstract}
This study has a focus on patterns of work related interactions, experiences and attitudes expressed by leaders in the Swedish Police force.

A cross-sectional design was used to compare police leaders $(n=106)$ with reference groups recruited for public and private enterprises $(\mathrm{n}=1650)$. Work related ratings were provided by use of a recruitment inventory JobMatch Talent (JMT). In this study, three main JMT scales (including subscales) concerned with relationships were used:

Tolerance (h1: Assent image, h2: Tolerant attitude, h3: Trust in others);

Social Interest (i1: Showing consideration, i2: Diplomacy, i3: Contact creating);

Communication (j1: Impact, j2: Communicativity, j3: Openness).

The scales were compared across the three groups (Police, Public, Private) with analysis of variance. Low-level scoring on the scales indicates restricted relationships whereas high-level scoring expresses open and closer relationships.

The results showed that there were significant differences among the three groups on four of the nine JMT scales. The highest ratings were concerned with Trust in others (h3) and Tolerant attitude (h2). As to group differences, the main trend was that the Public group significantly differed from the Private on three of the four scales: Tolerant attitude (h2), Trust in others (h3), Openness (j3). For the scale Contact creating (i3), the Police group differed significantly from both the Public and Private groups.

More specifically, the post-hoc tests showed that the Police group ratings were intermediate between of the Public and Private groups for Tolerant attitude (h2). (significantly different from both). Finally, the Police group was significantly different from the Public group on Trust in others (h3).

The present results were discussed in relation to effective leadership within the Swedish Police force.

Keywords: Police; Leadership; Personal communication; Tolerance; Social interest; Relationship; Public
\end{abstract}

\section{Introduction}

Police work consists of a complex and sensitive nature and comprises issues of law and order, as well as social service, ordermaintenance and peace-keeping tasks [1,2]. Moreover, it acts within situations that can change momentarily from ordinary, everyday work to dangerous life-threatening situations, both for officers and the public [3]. Above this, as stated within Sir Robert Peel's nine principles the police are required to maintain beneficial and trustfully relations with the general public to be able to retain approval for their actions and obtain assistance in solving crimes (UK Government, 2012). Therefore, leadership remains crucial for enabling the required good performance and managing this level of complexity [2,4,5]. Nevertheless, leadership is not just about management but also about presenting a role model and by one's own behavior to model the expected behaviors within the law-and-order organization. Research shows that it is of substantial importance to identify the right individual for this type of work since performance is associated with the individual's characters and that training has very little bearing, if any, upon eventual performance [6].

Leadership bears with it the responsibility of presenting a role model whereby certain management skills are important not just for the relationship towards co-workers but also for the maintenance of contact with stakeholders within the society and with the general public. In order to create an environment, both internal and external, that will lead to productive and effective policing, a 
form of leadership that enhances the public willingness to cooperate and assist the police in its work is expected (UK Government, 2012). Attitudes affect the individual's perception and behavior [7]. Leadership characteristics, such as a tolerant attitude towards others, trust in and consideration for others, as well as being able to create contacts and have the ability to create openness is therefore of consummate gravity. Tolerance towards others pertains with how others are allowed to exist and act. A tolerant attitude requires listening skills without condemnation even if it does not mirror one's own opinions [8]. Police officers' attitudes have been shown to be connected with the quality of arrests [9]. Moreover, personality characteristics have also influence tolerance towards minority groups [9]. It is therefore important to search for individuals presenting a tolerant attitude during recruitment, not only for police leadership positions but also for professional status of police officers. In order to achieve the cooperation between police and public [2], as stated in Sir Robert Peel's Nine Principles (UK Government, 2012), trust and empathy (empathy: the ability to understand and share the feelings of others, Oxford dictionary) are essential ingredients. Schipper et al. imply that trust and empathy present necessary ingredients to any interpersonal relationship [10]. Moreover, they indicate that empathy represents a basis for trust and that trust and empathy correlate with openness.

On the other hand, trust, may be characterised as cognitive and affective, whereby the cognitive trust reflects dimensions, such as reliability, honesty, and fairness whereas affective trust reflects a relationship wherein the concern about someone's welfare is an included ingredient [11]. The skill of trusting in others is connected to which attitude one embraces in interpersonal relations. Trusting may concern the expectation that an individual may maintain a relationship for moral commitment by acting trustworthily. It concerns that first thought when interacting encompasses the predisposition to think the 'best-or-the-worst' about an individual [8]. High levels of trust within a society, exerts vastly positive effects, such as openness, democratic stability, and feelings of stability $[12,13,14]$. When an organization is regarded as fair individuals will perceive trust even despite an asymmetry of power [14], as in the situation regarding the police and general public. As trust relates to how the individual acts in the company of others, coworkers or the public, this is an important factor when it comes to leadership and the role-model of collaboration with others, such as the general public. To build and maintain good relations presents an important aspect of being a leader and a police officer. Since trust is a result of past experiences of situations and interactions between two or more parties, it follows that these past experiences will predict future behavior. Therefore, trustworthy act do not solely concern one single situation but rather the entire organization, i.e. police, and how it will be perceived in future situations [14].

Consideration and the creation contact are two important factors showing a person's social interest and their ability to interact with other people. In the context of this study, we look at how the individual displays his or her consideration. Displayed consideration concerns how the leaders act and conduct themselves in their daily interrelationship and how they prioritize positive relationships with others [8]. Leaders showing consideration listener well and are consequently aware of each other's concerns, needs and abilities $[7,15]$. Consideration behaviors have been found to be one factor in promoting motivation and effectiveness. Moreover, employees with leaders who display an individualized behavior of consideration will be more willing to perform beyond expectations [12]. In the relationship between leaders and co-workers trust has been shown to be anteceded by procedural, interactional and distributive justice and is connected with outcomes, such as job performance and job satisfaction as well as organizational commitment [16]. Moreover, consideration behaviors include both respect, trust and to establish relations with coworkers [12,17]. Furthermore, trust is seen as an important element of consideration behaviors [18].

The individual characteristic of contact-creating indicates the extent to which individuals show interest and the need for connecting with others [8]. Effective policing is dependent upon the cooperation and compliance of the general public which implies the contrivance of a contact-network. Reliance upon the internet technologies for contact-contrivance internally and externally is insufficient; one is required to establish relationships [13]. Finally, openness concerns leaders' willingness to share both information and intrinsic thoughts and feelings [8]. In policing enterprises, openness and transparency are key elements. Openness concerns the propensity to share ones' thoughts and feelings without fear and to be willing to answer. On the other hand, transparency concerns the sharing of factual information about performance and outcomes internally, as well as with the stakeholders, society and the public. The culture of openness is enhanced when innovation, rather than traditional approaches or the disciplining of efforts at novel solutions, is of primary focus. Furthermore, openness is enhanced by individuals experiencing support and appreciation, when teamwork is fostered, communication is informal and decisions are entrusted rather than centralised [18]. Transparency in its turn is vital for police legitimacy and credibility $[2,19]$.

The purpose of the present study was to compare a group of police-leaders' personal attributes, linked to leadership, with those of executive leaders from private enterprise and public administration. There is a notable paucity of information relating police-leader characteristics with high-level leadership within other sectors of professional life.

\section{Method}

\section{Design}

A cross-sectional design was used to compare police leaders with chosen reference groupings from a norm group of leaders (public and private enterprises), who provided self-reports at time of recruitment through their responses to a recruitment inventory [8]. The items responded to and measured were related to personal features, attitudes and experiences of work life. 
Participants: Sample and reference groups: A sample of police leaders $(n=106)$ with mixed experience from leadership was compared to other groupings [14]. The criteria used for selection of reference groupings were (a) homogeneity as to occupational orientation, and (b) private or public employment. The last criteria crossed gave rise to two reference groupings ( $\mathrm{n}=1650)$. Thus, the whole group included 1756 cases.

The JobMatch Talent (JMT) inventory Personal attitudes to and experiences of job relations and characteristics are measured with the JMT. The JMT test is based on ten main scales, each presenting three subscales [21]. In this study, nine subscales concerned with relationships (Concurring image, Tolerant attitude, and Trust in others, from the main scale "Tolerance"; Displayed Consideration, Diplomacy, and Contact creation, from the main scale "Social Interest"; Impact, Communicativity, and Openness from the main scale "Communication") were used. The subscales were chosen as they are attributes important for their representation of an open, supportive and flexible leadership that is sustainable and an important part of leadership role modelling.

\section{Statistical procedure}

The JMT scales were compared across the three groups (Police, Public, Private) with analysis of variance. If the main test was significant the three groups were anayzed with the Tukey B post-hoc test (using alpha=.05).

\section{Results}

There were significant differences among the three groups on four out of the nine JMT scales. For these four scales, the highest ratings were concerned with Trust in others-h3 and Tolerant attitude-h2. See Figure 1 for an overview of the mean ratings of the groups.

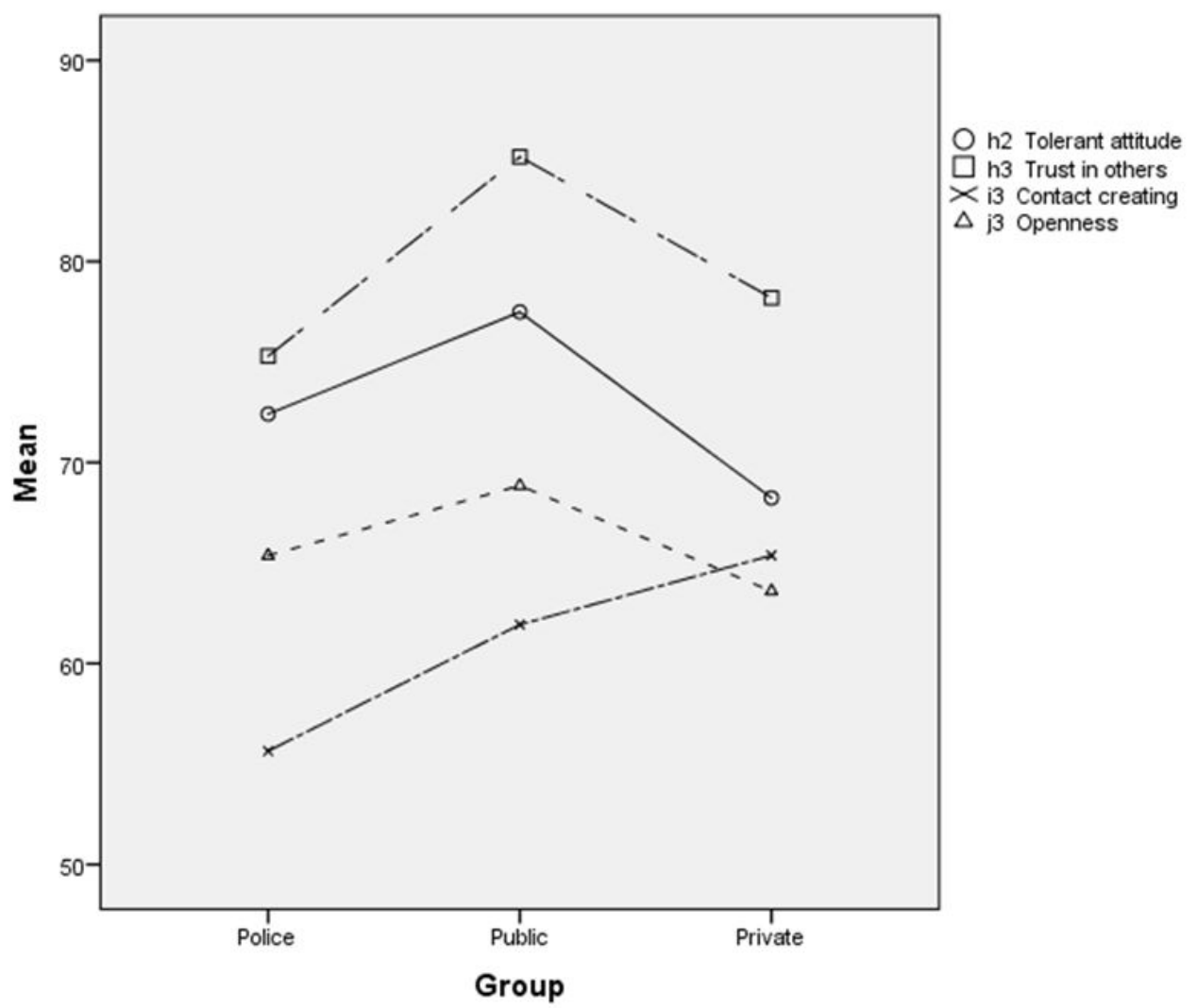

Figure 1: Mean ratings for the Police $(n=106)$, Public $(n=822)$ and Private $(n=828)$ groups on the JMT scales Tolerant attitude-h2, Trust in others-h3, Contact creating-i3, Openness-j3 N=1756). See Figure 1 for an overview of scale

The main trend was that the Public group (PUB) significantly differed from the Private (PRI) on three of the four scales: Tolerant attitude-h2 $(\mathrm{F}(2,1753)=50.23, \mathrm{p}<.001$; eta-squared=,054), Trust in others-h3 $(\mathrm{F}(2,1753)=28.44, \mathrm{p}<.001$; eta-squared=,031), Openness-j3 $(\mathrm{F}(2,1753)=13.24, \mathrm{p}<.001$; eta-squared=,015). For the scale Contact creating-i3, the Police group (POL) differed significantly from both PUB and PRI $(\mathrm{F}(2,1753)=12.97, \mathrm{p}<.001$; eta-squared=,015). More specifically, the post-hoc tests showed that the POL group ratings were in between of the PUB and PRI groups for Tolerant attitude-h2 (significantly different from both). In addition, the POL group was significantly different from the PUP group on Trust in others-h3. See Table 1 below for an overview of the post-hoc tests.

See Figure 1 for an overview of scale profiles based on mean ratings across the groups. In more detail, mean and standard deviation of the scales are shown in Table 1. 


\begin{tabular}{|c|c|c|c|c|c|}
\hline \multicolumn{2}{|c|}{ Groups } & $\begin{array}{c}\text { Tolerant } \\
\text { attitude }\end{array}$ & $\begin{array}{c}\text { Trust in } \\
\text { others }\end{array}$ & $\begin{array}{c}\text { Contact } \\
\text { creating }\end{array}$ & Openness \\
\hline \multirow{4}{*}{ Police } & Mean & $\mathbf{7 2 , 4 1}$ & $\mathbf{7 5 , 2 9}$ & $\mathbf{5 5 , 6 4}$ & $\mathbf{6 5 , 3 7}$ \\
\cline { 2 - 6 } & Std. Deviation & 17,821 & 20,612 & 22,539 & 20,476 \\
\cline { 2 - 6 } & $\mathrm{N}$ & 106 & 106 & 106 & 106 \\
\hline \multirow{4}{*}{ Public } & Mean & 77,48 & 85,20 & 61,93 & 68,85 \\
\cline { 2 - 6 } & Std. Deviation & 17,855 & 19,183 & 20,265 & 20,070 \\
\cline { 2 - 6 } & N & 822 & 822 & 822 & 822 \\
\hline \multirow{4}{*}{ Private } & Mean & 68,24 & 78,19 & 65,38 & 63,60 \\
\cline { 2 - 6 } & Std. Deviation & 19,697 & 22,100 & 21,232 & 21,542 \\
\cline { 2 - 6 } & N & 828 & 828 & 828 & 828 \\
\hline \multirow{3}{*}{ Total } & Mean & 72,82 & 81,30 & 63,18 & 66,16 \\
\cline { 2 - 6 } & Std. Deviation & 19,263 & 21,014 & 21,009 & 20,945 \\
\cline { 2 - 6 } & N & 1756 & 1756 & 1756 & 1756 \\
\hline
\end{tabular}

Table 1: Means and standard deviations for the four JMT scales tolerant (h2), Trust in others (h3), Contact creating (i3), Openness (j3) across the three groups Police $(n=106)$, Public $(n=822)$ and Private $(n=828)$

See Table 2 below for an overview of the post-hoc tests.

\begin{tabular}{|c|c|}
\hline Scale & Tukey $\mathbf{B}$ post-hoc $(\mathbf{p}<.05)$ \\
\hline Tolerant attitude & PRI $<$ POL $<$ PUB \\
\hline Trust in others & $(\mathrm{POL}$ and $\mathrm{PRI})<\mathrm{PUB}$ \\
\hline Contact creating & $\mathrm{POL}<(\mathrm{PUB}$ and $\mathrm{PRI})$ \\
\hline Openness & $\mathrm{PRI}<\mathrm{PUB}$ \\
\hline
\end{tabular}

Table 2: Differences among the Police group $(\mathrm{n}=106)$ and the control groups Public $(n=822)$ and Private $(n=828)$ for the four JMT scales Notations. $\mathrm{POL}=$ Police, $\mathrm{PUB}=\mathrm{Public}, \mathrm{PRI}=$ Private.

\section{Discussion}

The self-reported attributes of police leaders differed from those of the private leaders and public leaders, respectively, through diverse respects (see above). Predictive policing implies the application of mathematical, predictive and analytical techniques in law enforcement to identify potential criminal activity but also the use of the notion of 'other-perspective' which is associated with empathy [21] in order to attain the goal of "stopping crime before it starts" [22]. Police executives focus upon 'contact-creation' was markedly lower than that of the private and public sectors (see Table 1). As yet the law enforcement agency, as represented by the present sample, has not understood the essential role of contact-creation. For example, the paucity of informal and formal support for women experiencing domestic violence and abuse will improve safety and health outcomes in addition to bringing offenders to justice [23].

As stated above, police work is complicated and complex $[1,2,3]$. To create effective police work, the police force is dependent on good relations with the public, as first stated in Sir Robert Peels nine principles published around 1880 (UK Government, 2012). Moreover, as coworkers model leadership behavior [24] leadership is crucial for good relations with the public and effective police work to happen $[2,4,5]$. Leadership within the police concerns trust and empathy to great extent whereby leadership role-models behaviors that enhance trust, showing consideration and tolerance for others, and enabling openness and creates contacts, as well as officers modeling that behavior when interacting with the public. Huberts et al. [24] found that employees mimic the leader's integrity standards and that modeling was especially important in limitation of unethical conduct. Nevertheless, the process covers not just one specific officer and one specific citizen in one specific situation, but rather as positive experiences develop, trust spreads and induces an expectation of positive and fair treatment affecting the whole police department. Successful policing spreads and enhances the necessary trust and cooperation between the police and general public thereby enhancing the value of individual leadership characters, such as capability to build trust, tolerance, consideration and the ability to create connections.

The quality of the service that is delivered by the employees of an organization is affected by its leadership [25] It has been found that performance is related to personality attributes and that training exerts a limited influence upon enhanced performance in jobs where cognition is central to the solution of work tasks, as in the police force [21]. Therefore, it is important to identify the right person for this position through recruitment procedures that focus on leadership characteristics instead relying upon training to enhance individuals to positive leadership capability. One aspect of leadership deals with the relation to others (internal to coworkers, external to stakeholders and the public). Research has shown that personality attributes, such as extroversion, are more tolerant against minority groups than, for instance, neuroticism [9]. Moreover, research has found that self-fulfilling individuals, expressing high positive and low negative affect encompassing high levels of optimism, energy and self-esteem [20] display: tolerant attitude towards others; trust in others, considerational behavior, contact creating and openness). 
The role model aspect of leadership, intrinsic to effective policing, is often neglected. The result shows that there are significant differences between police leaders and one of the two other leadership groups (public and private) in three out of five characteristics. Police leaders expressions differ significantly from private and public regarding tolerant attitude and contact creating, while differing significantly to public leaders regarding trust in others. Since the police organization is a public organization, one would assume that the results of the police leaders would accompany those of other public leaders. This is not the case. The result shows that police leaders have the lowest levels of contact-creating behavior and trust in others, critical factors not only when it comes to leadership but also in establishing relations with the public. One may argue that the trust in others may be associated with disappointment when constantly dealing with individuals of a criminal nature but when this extends to leadership and the relation to co-workers it also has the chance to extend towards those of the non-criminal public whom the police are in great need of to have a positive relation with. Another factor related to the relation is openness whereby police leaders as leaders of a public organization would have been assumed to be open and transparent. In this case, the result shows that even though private and public domains significantly differ from one another, public with the higher levels, police leaders did not significantly differ from any of those groups.

A comparison of the present results and those from [21], depicting police leaders' significantly lower tolerance to stress, enterprise and inner drive, provokes a vision of police leaders with leadership problems that may be reflected in the manner in which coworkers lack leadership attributes in confrontation with the general public. Despite the existence of sound leadership within the Swedish Police force, the result shows that there is a problem with police leaders lacking the characteristics required for the role modeling good police behavior. The admirable work performed by the Swedish police during the Stockholm terrorist attack in the spring of 2017 were more the consequence of individual police officers initiating commendable judgment than any effective organizational or leadership qualities displayed by the administration.

\section{References}

1. Holgersson S, Knutsson J (2010) Dialogue policing - a means for less collective violence? Crime Prevention Studies: Preventing Collective Violence. Cullompton: Willan Publishing.

2. Van Dijk A, Hoogewoning F, Punch M (2015) What matters in policing? Change, values and leadership in turbulent times. Bristol, Bristol University, Policy Press.

3. Casey J, Mitchell M (2007) Police leadership and management. Sydney, Federation Press.

4. Dobby J, Anscombe J, Tuffin R (2004) Police leadership: expectations and impact. Home Office: London.

5. Boedeker C, Vidgen R, Meagher K, Mouritsen J, Runnalls M (2011) Leadership, culture and management practices of high performing workplaces in Australia: The high performing workplaces index. Society for Knowledge Economics, Sidney.

6. Kajonius P (2015) An inquiry into satisfaction and variations in user-oriented elderly care. Doctoral Dissertation University of Gothenburg.

7. Simone D (2011) The influences of supervisor's leadership styles on subordinate police officer's productivity in an urban New Jersey police department. (Order No. AAI3438511). Available from PsycINFO

8. Olsen K (2017) Jobmatch Interpretation Manual English Master.pdf

9. Zalenski Z, Eysenck S, Eysenck H (1995) Personality and attitudes towards marginal social groups. Personality and individual differences 18: 677-79

10. Schipper M, Bartholdi K, Schauber M, Peterman F (2014) Relations between empathy, trust, and personality traits differ between collectivism and individualism. Retrieved on 2 of June 2017.

11. McAllister DJ (1995) Affect- and cognition-based trust as foundations for interpersonal cooperation in organizations. Acad Manag J 38: 24-59.

12. Gözübenli M (2009) An investigation of leadership styles in a large American police department: Effects on officers' extra effort, perceptions of leader effectiveness, and satisfaction with leaders. (Doctoral Dissertation). Retrieved from UMI Dissertaion Publishing, ProQuest LLC. UMI Number: 3390246

13. Axelrod RH (2010) Terms of engagement. New ways of leading and changing organizations. San Francisco, Berrett-Koehler Publisher.

14. Oskarsson S, Svensson T, Öberg PO (2009) Power, trust, and institutional constraints. Rationality and Society 21: 171-95.

15. Bass BM, Avolio BJ (2004) Transformational leadership development: Manual for the Multifactor Leadership Questionnaire. Palo Alto, CA: Consulting, Psychologists Press

16. Dirks KT, Ferrin DL (2002) Trust in Leadership: Meta-Analytic Findings and Implications for Research and Practice. J Appl Psychol 87: 611-28.

17. Stogdill R, Coons AE (1957) Leader behavior: Its description and measurement. Columbus, OH: Bureau of Business Research, The Ohio State University.

18. Davies TO, Nutley S, Manion R (2000) Organisational culture and quality of health care. Quality in Health Care 9: 111-9.

19. Neyroud P, Beckley P (2001) Policing, ethics and human rights. Cullompton: Willian

20. Archer T, Adolfsson B, Karlsson E (2008) Affective personality as cognitive-emotional presymptom profiles regulatory for self-reported health predispositions. Neurotoxicity Research 14: 21-44

21. Andersson Arnten AC, Jansson B, Olsen K, Archer T (2017) Self-reported Attributes of Police-chiefs Compared to Civil Leadership: Inner drive, Tolerance to stress and Enterprise. J Foren Res 8: 1.

22. Malik A, Maciejewski R, Towers S, Mc Cullough S, Ebert DS (2014) Proactive Spatiotemporal Resource Allocation and Predictive Visual Analytics for Community Policing and Law Enforcement. IEEE Trans Vis Comput Graph 20: 1863-72.

23. Evans MA, Feder GS (2016) Help-seeking amongst women survivors of domestic violence: a qualitative study of pathways towards formal and informal support. Health Expect 19: 62-73.

24. Huberts LWJC, Kaptein M, Lasthuizen K (2007) A study of the impact of three leadership styles on integrity violations committed by police officers. Policing 30: 587-607.

25. Baker TE (2006) Effective police leadership. Moving beyond management. Flushing NY: Loosleaf Law Publishing. 


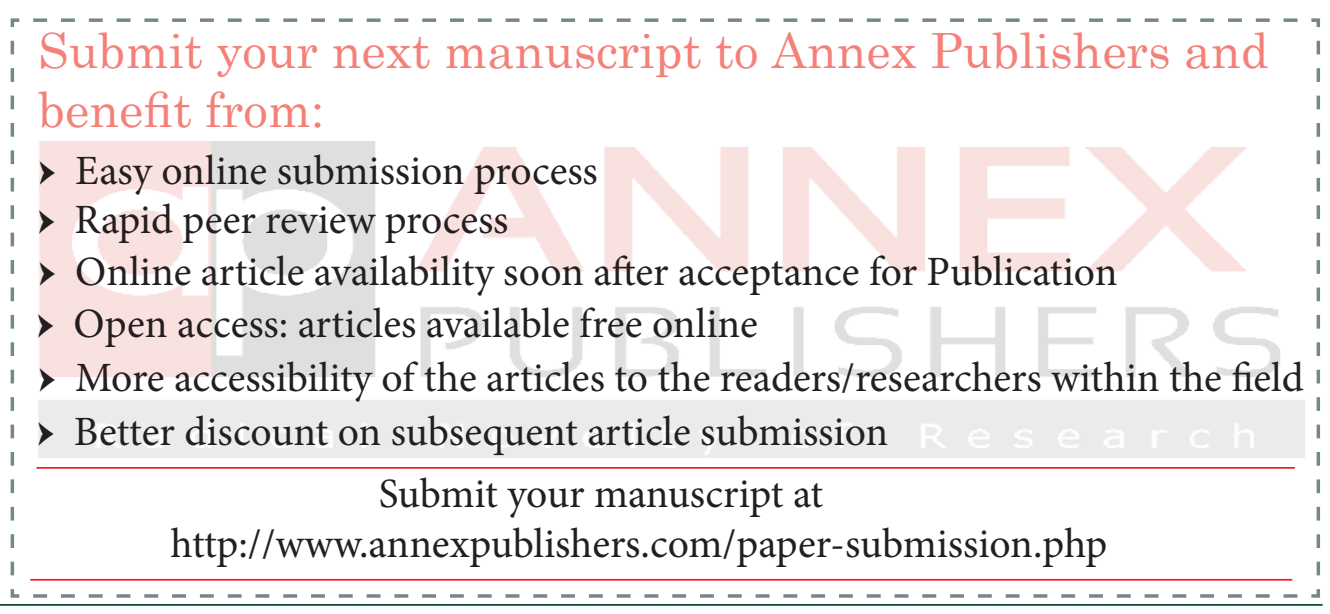

